\title{
An Analog Model of Neutral-to-Earth Voltages in a Single- Phase Distribution System
}

\author{
LAVERNE E. STETSON, MEMBER, IEEE, GERALD R. BODMAN, AND HOLLIS SHULL
}

\begin{abstract}
An analog model has been developed to illustrate the neutral-to-earth voltage phenomenon associated with multigrounded single-phase distribution systems. The model can be used to demonstrate the effects on primary lines of magnitude and location of loads with respect to the substation, poor neutral connections, and poor grounds. On secondary lines the effects of poor connections, poor grounds, and undersized neutrals can be illustrated with two farmstead loads. These loads can be connected to illustrate the effects of loads in phase and out of phase with the primary line and the influence of one farm on another. The effect of separating primary and secondary neutrals can be illustrated.
\end{abstract}

\section{INTRODUCTION}

$\mathbf{N}$ EUTRAL-TO-EARTH (NTE) voltage on single-phase distribution neutrals develops because of multiple grounding of primary and secondary neutral conductors. NTE voltage, referenced by various names including stray voltage and extraneous voltage, has been reported from many parts of the world in research reports dating back to the 1940's. Many reports have been referenced in research papers, e.g., Fairbanks and Craine [1], Henke et al. [2], and Stetson et al. [7] . Gustafson and Craine prepared a bibliography regarding NTE voltages in livestock shelters that was appended to a report by McClernon et al. [3]. The bibliography lists 61 reports and publications, six extension publications, and 50 related technical papers and publications.

NTE voltages sometimes appear within confined livestock structures, such as milking parlors and farrowing units. Livestock are very sensitive to electric current [4]. Voltage differences as low as $0.5 \mathrm{~V}$ may cause animal discomfort. Dairy cows become agitated, produce less milk, and become more susceptible to mastitis infection when subjected to NTE voltages. The purpose of this paper is to describe a model which permits orderly analysis of the NTE problem.

\section{PROBLEM DIAGNOSIS}

Many NTE voltage reports describe the results of field investigations. Research personnel are requested to investi-

Paper REPC 83-01, approved by the Rural Electric Power Committee of the IEEE Industry Applications Society for presentation at the 1983 Rural Electric Power Committee Conference, Des Moines, IA, April 24-26. Manuscript released for publication June 24, 1983.

L. E. Stetson is with the Agricultural Research Service, U.S. Department of Agriculture, University of Nebraska, Lincoln, NB 68583-0729.

G. E. Bodman is with the Cooperative Extension Service, University of Nebraska, Lincoln, NB 68583-0726.

H. Shull was with the Agrícultural Research Service, U.S. Department of Agriculture, University of Nebraska, Lincoln, NB. He is now retired. gate an NTE voltage problem that has not been solved by field personnel. The researchers go to the site and obtain data by visual inspection and electrical measurements. They analyze the data and suggest steps to alleviate the problem. The procedure does not always produce a solution, but unsuccessful investigations are seldom reported. In most cases, however, the investigator reports that he understands the elements involved in the NTE voltage phenomenon and that he followed some logical and orderly procedure in an attempt to obtain a solution.

An orderly approach to NTE voltage investigations is needed because the source of the voltage is often difficult to find. It may have one cause, or there may be several. There may be only an on-farm or an off-farm source, but in most cases both exist. NTE sources are usually found through a process of elimination. The elimination process is facilitated by an orderly evaluation procedure.

To help those who do not have NTE voltage experience, researchers began to include in their reports step-by-step procedures for obtaining and analyzing data and developing a solution to the problem. With time and better understanding of the NTE problem, these procedures have lengthened and become more complex. Instead of a fixed set of step-by-step procedures, we have developed a flow diagram to help assure orderly diagnostic procedures. Pertinent measurements are made and data are evaluated to determine the next step in the analysis. The investigator follows through the flow diagram in much the same way as a computer follows a program as it searches for a problem solution. The flow diagram might well be considered the second generation attempt to develop an orderly approach to solving NTE problems. In addition to the flow chart, personnel investigating NTE voltages must have adequate understanding of electrical system theory and safety practices and use appropriate test equipment.

The basic concept of NTE voltage development is not difficult to grasp. NTE voltages develop because the primary and secondary neutral conductors are attached to the earth at intervals, and therefore some neutral current flows through the earth. Both the conductor and the earth resist electric current flow. Current flows through a resistance because of a voltage difference across it. The voltage difference between the earth and the neutral conductor is the NTE voltage. A complicating factor is the interaction between the many NTE circuit paths along the distribution system. A change in any part of the interconnected neutral-conductor multiplegrounded network affects all parts of the network to some degree. For example, a farm with no NTE voltage may sud- 
denly have a problem if the secondary neutral current at a neighboring farm changes phase with respect to the primary neutral current. It is this interaction between all parts of the distribution system that makes the understanding and analysis of NTE voltage problems so difficult.

Electricians and power company crews who are faced with an NTE voltage situation are often not prepared for lowvoltage problems. Their training and daily concerns are mainly with secondary voltages of 120,240 , or $480 \mathrm{~V}$ or primary voltages of $7200 \mathrm{~V}$ or more. Because of this, some researchers have resorted to a simple analog to explain the development of NTE voltage. One analog uses the "true-earth" concept [3], [5], [6]. The analog assumes that each connection between the neutral conductor and earth ground can be represented by a resistance between the conductor and true earth. True earth has zero resistance, and zero potential difference exists between any two true-earth ground connections regardless of their physical spacing. True earth is used as a voltage reference. While the true-earth analog is not an exact model of a multiple grounded electrical distribution system, it does develop NTE voltage in much the same way as occurs in the field and is, therefore, a valid simplification capable of demonstrating the NTE voltage phenomenon.

The true-earth model was adopted to a simple electrical analog comprising an isolated length of multiple grounded primary neutral and two farm loads. Our analog was designed to serve as an NTE demonstration unit to acquaint field personnel with the major factors involved in NTE investigations.

\section{ANALOG DESCRIPTION}

Figs. 1 and 2 show schematic diagrams of the analog circuits. The primary circuit is shown in Fig. 1. Twelve line resistances $\left(R_{\mathrm{PN}}\right)$ and 13 ground resistances $\left(R_{\mathrm{PG}}\right)$ are used to represent a section of primary neutral line. Tap connections are available between each line segment and ground. Each ground resistance can be varied from 1 to $256 \Omega$, and each line segment resistance can be varied from 0.1 to $6.2 \Omega$ by selecting positions of the dual in-line package (DIP) switches.

Two secondary neutral circuits of the type shown in Fig. 2 were constructed on the analog board to illustrate the effects of neutral currents from farm loads. Two secondary circuits demonstrate interactions between farmsteads. Each secondary line resistance can be varied from 0.1 to $6.2 \Omega$ and each secondary ground can be varied from one to $256 \Omega$ by DIP switch settings. A switch on the secondary ground $\left(R_{\mathrm{GT}}\right.$ in Fig. 3) permits removal of that ground when that circuit is connected to the primary neutral.

Use of the DIP switches permitted compact packaging of the analog components. All of the components are mounted on an $81 \times 56 \mathrm{~cm}(32 \times 22$ in $)$ board. The depth of the assembled model is $13 \mathrm{~cm}(5 \mathrm{in})$, which includes a rear and a front cover. The rear cover protects the wired components, and the front cover protects knobs and switches and also folds out as a support. This assembly allowed safe and convenient storage or transporting for use at meetings and workshops.

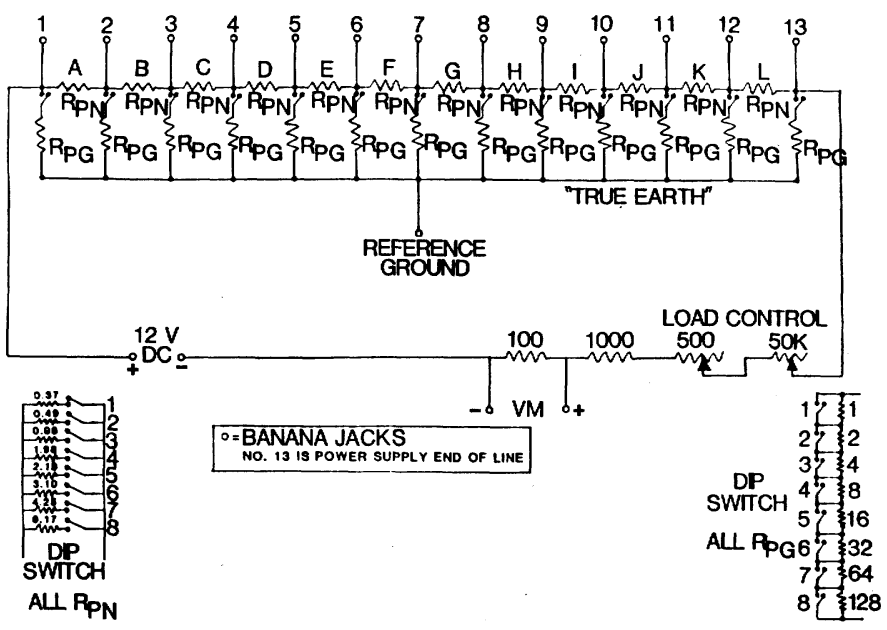

Fig. 1. Schematic diagram of primary side of NTE voltage analog of single-phase distribution and resistor connections to dual in-line package (DIP) switches.

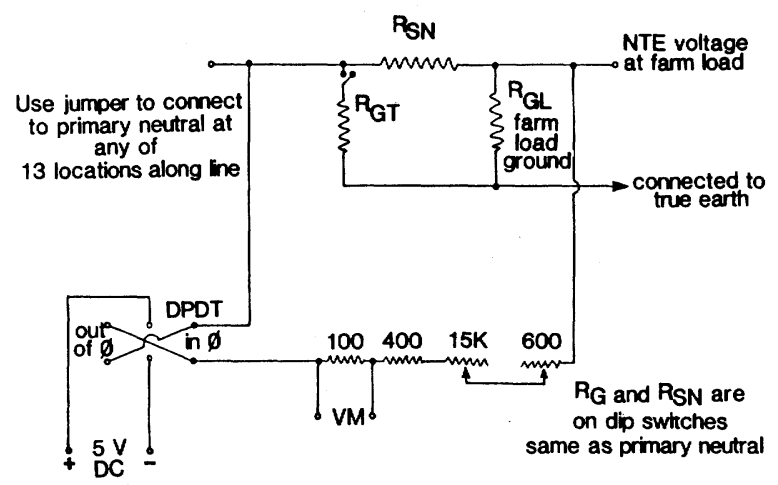

Fig. 2. Schematic diagram of secondary side of NTE voltage analog of single-phase distribution system.

The component layout of the analog model is shown in Fig. 3.

DC instead of ac was used to power the analog so that relative current flow direction could be demonstrated. Use of $\mathrm{dc}$ required that the power supplies to the primary and two secondaries be isolated from each other. Interconnecting the primary and secondary neutrals, as is common practice in the field, is achieved with jumpers from either of the secondary neutral taps to any one of the 13 primary neutral taps.

A phase switch reverses the secondary neutral current flow direction. This simulates the $180^{\circ}$ phase shift found in $120 /$ $240-\mathrm{V}$ transformers which are commonly used on farmsteads. Current is considered in phase when it flows from the transformer to farm load in the same direction as from location 13 to 1 in the primary analog (Fig. 1). Because the analog is dc-powered, inductive and capacitive effects cannot be demonstrated.

The analog has no provision for simulating defective equipment but can simulate improper wiring, such as high neutral conductor resistance and poor grounding practices. It is most useful for showing the effects of primary and secondary neutral currents of different magnitudes and phase relationships. 


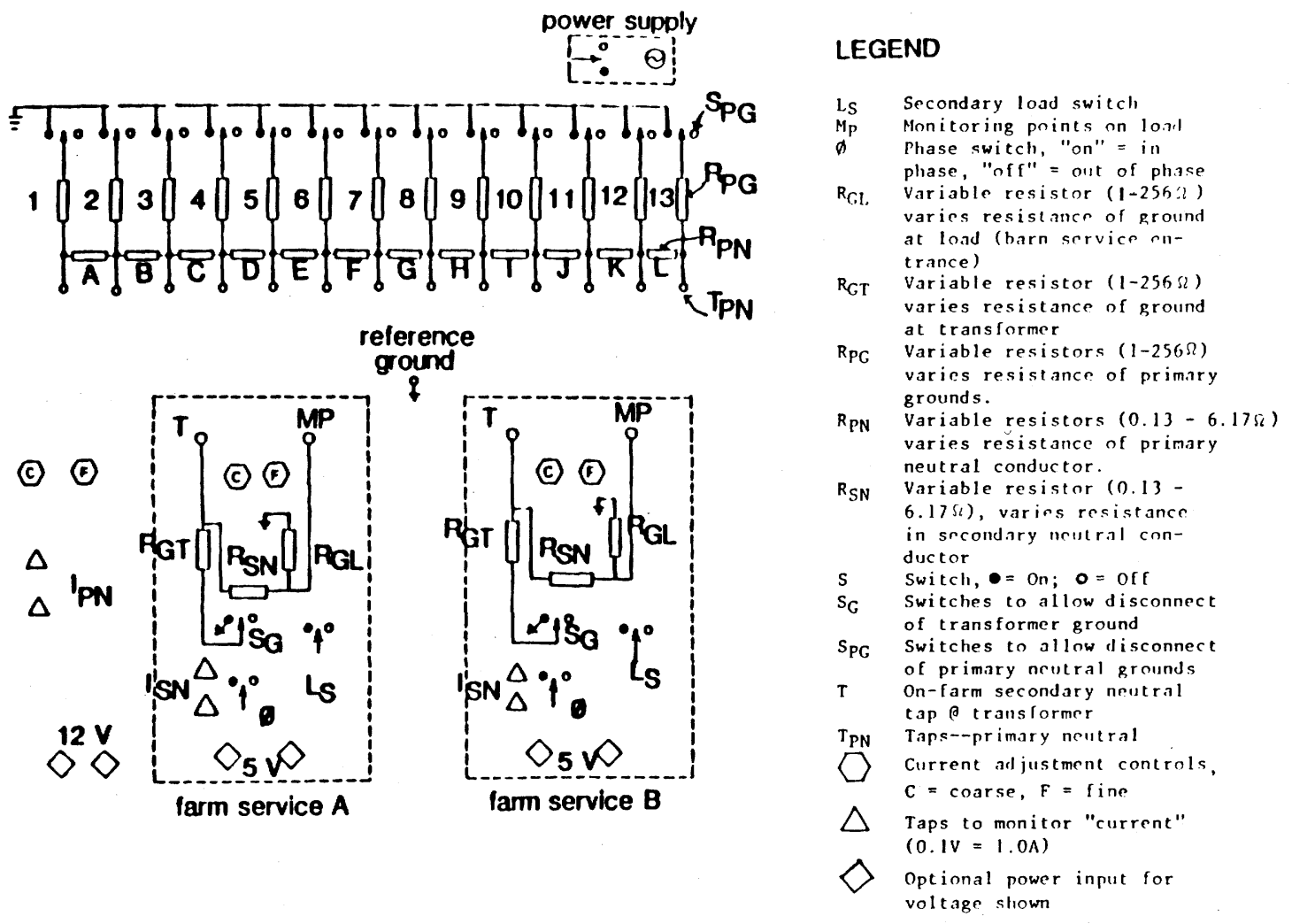

Fig. 3 Model layout of distribution line and farmstead loads.

\section{ANALOG DEMONSTRATIONS}

The following are some selected interactions that can be demonstrated with the analog.

1) The effect of primary conductor resistance on NTE voltage demonstrates the influence of neutral wire size.

2) The effect of a high resistance at some location along the primary or secondary neutral conductor demonstrates the effect of a high-resistance splice or connection.

3) The effect of different neutral-to-earth resistances on NTE voltage demonstrates the effect of good and poor grounding.

4) The effect of connecting a farmstead neutral at different locations along the primary neutral demonstrates that farm NTE voltage can be location-dependent.

5) The effect of the phase of the second neutral current and load ground resistance on NTE voltage on both farms at the farm load demonstrates the interaction between farmsteads and the interactions of secondary and primary neutral currents when in phase and out of phase.

6) The effect of connecting or disconnecting the farmstead neutral from the primary neutral demonstrates the installation of an isolating transformer.

Results obtained from the selected demonstration follow.

\section{Demonstration 1}

This demonstrates the effect of different neutral conductor sizes on NTE voltage. The analog was operated with resistance values of $0.2,0.4$, and $0.6 \Omega /$ segment, with a primary current of $1 \mathrm{~A}$ and all ground resistances of $16 \Omega$. The results of these tests are shown in Fig. 4 where voltages are shown with respect to line location.

The voltage drop along the line and the NTE voltage increase as neutral conductor resistance increases. For the isolated line segment represented by the analog, the NTE voltage was maximum at the ends of the line and minimum at or near the center. On an actual primary transmission line, the uniform changes in NTE voltage measured with the analog would not occur because the circuitry would not be isolated or balanced. However, the interactions demonstrated by the analog have been confirmed by field investigations. That an increase in NTE voltage occurs toward the end of a distribution line was reported by Szelich [9]. NTE voltage problems on farms that are near substations have also been investigated.

\section{Demonstration 2}

This demonstrates the effect on NTE voltage of a highresistance splice or connection in the primary neutral conductor. Primary current and ground resistances were the same as Demonstration 1. Fig. 5 gives the results when the resistance of segment $F$ (Fig. 1) is changed to $0.6 \Omega$ and all other segments are left at $0.2 \Omega$.

This shows that the voltage drop across segment $F$ is much greater than across any of the other $R_{\mathrm{PN}}$ segments. The increased drop across the high-resistance segment increased the total voltage drop across the line from 2.1 to $2.3 \mathrm{~V}$ when compared to the test with all conductor resistances of $0.2 \Omega$. The NTE voltage (absolute value) at all tap connections was increased by the high-resistance section. 


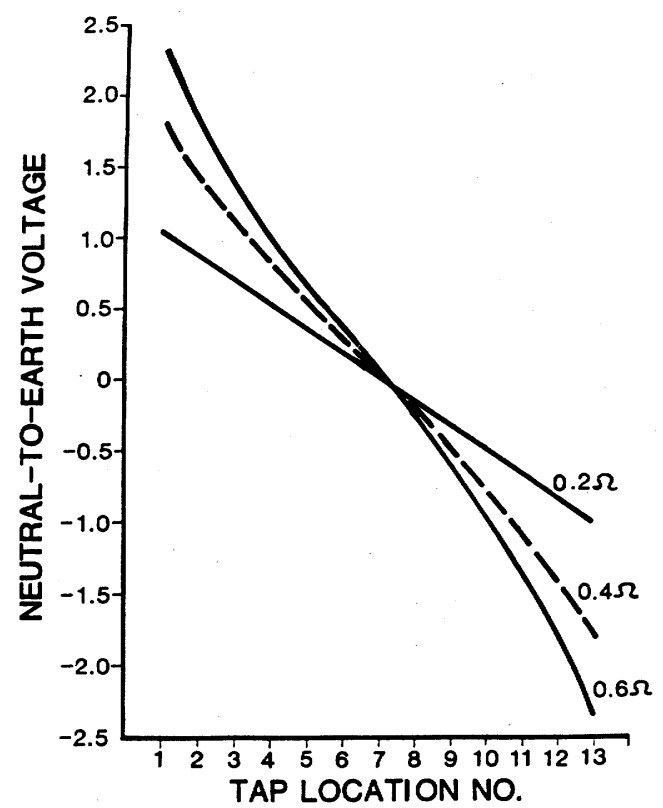

Fig. 4. NTE voltage for selected neutral conductor resistances as functions of line location from power supply. Primary neutral current is $1 \mathrm{~A}$. All ground resistances are $16 \Omega$.

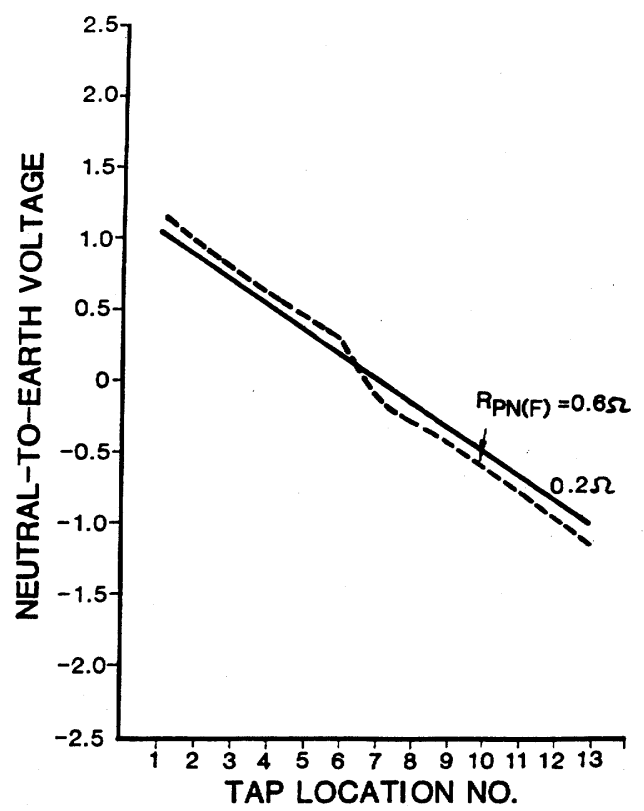

Fig. 5. NTE voltage for all neutral conductor resistances of $0.2 \Omega$ and for neutral conductor segment $(F)$ of $0.6 \Omega$. Primary neutral current is $1 \mathrm{~A}$. Remaining primary neutral resistance is $0.2 \Omega /$ segment.

The effect of a high-resistance primary neutral connection was described by Szelich [9] . He found that correcting a highresistance neutral line connector reduced the NTE voltage at the end of a transmission line from 45.4 to $10.0 \mathrm{~V}$. Field studies by the authors (Stetson et al. [8]) have also verified that replacing high-resistance primary neutral connections in an area with high soil resistance reduced the NTE voltage near the end of a distribution line.

\section{Demonstration 3}

This demonstrates the effect of $R_{\mathrm{PG}}$ changes on NTE voltage. Results are given in Fig. 6 . The voltage profile for the

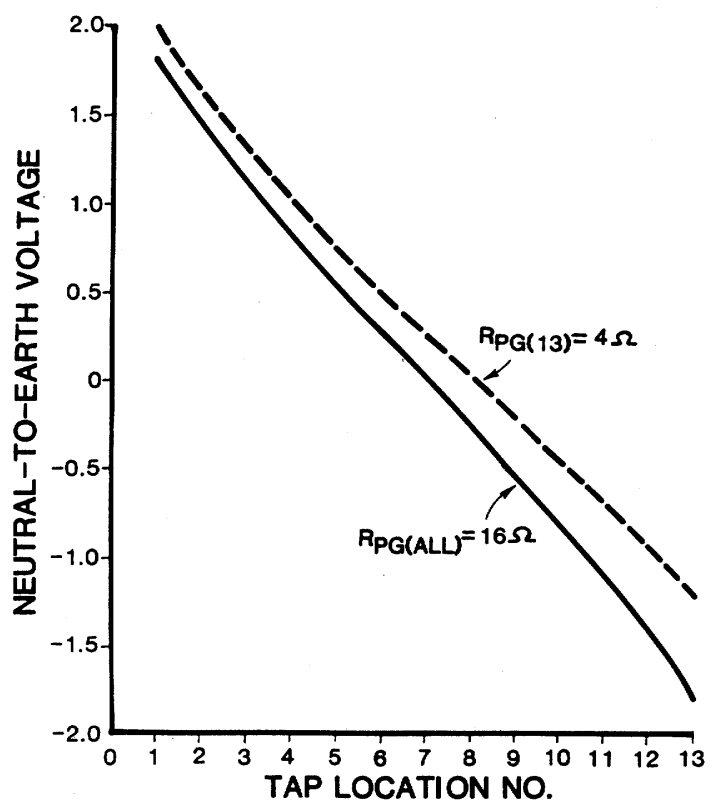

Fig. 6. NTE voltage for selected ground resistances as function of line location from power supply. Primary current is 1 A. Primary neutral resistance is $0.4 \Omega /$ segment.

system when only $R_{\mathrm{PG} \mathrm{(7)}}$ was changed to $4 \Omega$ was identical with the profile with all ground resistances of $16 \Omega$. Changing $R_{\mathrm{PG}(13)}$ to $4 \Omega$ reduced the voltage at tap 13 but increased the voltage at the opposite end.

It is apparent from Fig. 6 that ground resistance changes can cause NTE voltage changes, but the effect is locationdependent. With all $R_{\mathrm{PN}}$ the same and all $R_{\mathrm{PG}}$ the same, the current flow through $R_{\mathrm{PG} \text { (7) }}$ is very low. Therefore, $R_{\mathrm{PG} \text { (7) }}$ can be changed or disconnected with little effect on the other NTE voltages. When the $R_{\mathrm{PG}}$ change is at one end of the analog line, observable voltage changes occur. For example, a reduced $R_{\mathrm{PG} \text { (13) }}$ decreases the NTE voltage at taps $8-13$ but increases it at the other taps. However, the overall effect is a reduction of the maximum voltage difference. This demonstrates that ground resistance changes on a line may increase, decrease, or have little effect on NTE voltage at other locations.

\section{Demonstration 4}

For this demonstration a single farm load was connected to the primary system. This demonstrated the effect of secondary neutral connection location, primary-secondary neutral current phase relationship, and the effect of a balanced secondary neutral load on NTE voltage at the farm load location. Test conditions were as follows: primary current $=$ $1 \mathrm{~A}$, primary neutral resistance $=0.4 \Omega /$ segment, primary ground resistance $=16 \Omega /$ ground, secondary neutral resistance $=0.2 \Omega$, and secondary neutral current $=1 \mathrm{~A}$ for phase relationship tests and $0 \mathrm{~A}$ for voltage due to line location only.

Results of this demonstration are presented in Fig. 7. These data show that farm load NTE voltage can be linelocation-dependent as well as farm-load-dependent. Also, an interaction takes place between secondary neutral current phase and location. With no secondary neutral current, an offfarm source is responsible for the farm load NTE voltage. 


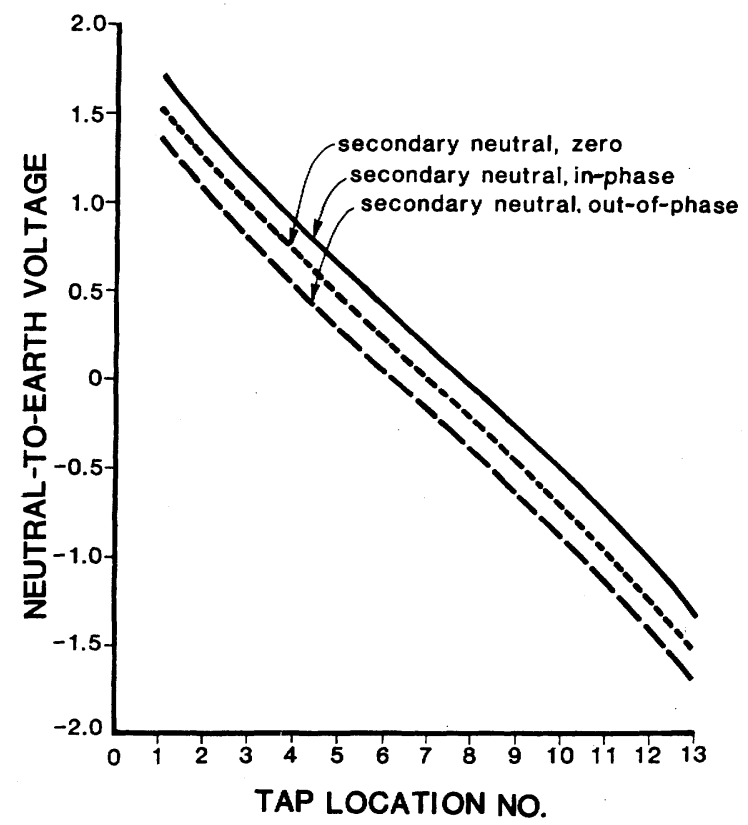

Fig. 7. NTE voltage for secondary neutral currents of $1 \mathrm{~A}$ in-phase and out-of-phase with primary neutral current and with no secondary neutral current. Primary current is $1 \mathrm{~A}$. All ground resistances are $16 \Omega$. Primary line resistance is $0.4 \Omega /$ segment. Secondary line resistance is $0.2 \Omega$.

With both on-farm neutral current and an off-farm source, the phase relationship between the primary and secondary neutral currents and the line location affect the farm NTE voltage.

\section{Demonstration 5}

This demonstration illustrates the complexity of determining causes of NTE voltage because it shows that changes in electrical conditions on one farm can cause NTE voltage changes on another farm. Conditions such as ground resistances at each farm, position along the primary line, and the magnitude and phase relationships of secondary neutral currents on each farm are major factors.

The analog was operated with two farm loads connected to the primary neutral. Farm A with $2.4 \mathrm{~A}$ of neutral current was connected at tap 2, and farm B with $8.0 \mathrm{~A}$ of neutral current was connected at tap 4 . The primary current was set at $1 \mathrm{~A}$. Variables were farm load grounding resistance and the in-phase, out-of-phase relationships of secondaryto-primary neutral current. All analog conditions and demonstration results are given in Table $I$.

For test A, farm B was not affected by farm A because the only NTE voltage changes at farm $B$ were caused by the phase relationship at farm B. However, farm A was affected by farm $B$. The NTE voltage on farm A was highest when the neutral current on farm B was out-of-phase with the primary current.

For test B, farm B was affected by farm A, as farm A had less ground resistance at the farm load, but the same neutral current as for test $\mathbf{A}$. In this second test, farm B, with the higher ground resistance, affected farm $\mathrm{A}$ when the secondary neutral current at farm B was switched from in-phase to outof-phase.
The data in Table I suggest that farms with higher ground resistance at the load centers are more affected by neighboring farms with low ground resistance at their load centers. Low resistance grounding at a livestock structure is important to reduce NTE voltage at that structure. Location of one farm with respect to another as related to the length of primary line and primary line loading are complicating factors. Tests with identical neutral current at each farm, with farms at different taps, show that interaction magnitude decreases as the distance between farms increases.

\section{Demonstration 6}

The purpose was to demonstrate the effect of connecting and disconnecting the secondary neutral from the primary neutral at the transformer pole. Disconnecting the secondary neutral produces conditions similar to installing an isolating transformer. Results are given in Table II.

From the tests with only one secondary neutral connected to the primary neutral it is evident that both farms A and B developed some on-farm NTE voltage. Farm A developed $0.9 \mathrm{~V}$ and farm $\mathrm{B}$ developed $0.3 \mathrm{~V}$. With the test current and resistances used, those voltages would be present if an isolating transformer were installed. Also, connecting the primary and secondary neutrals sometimes reduced and sometimes increased the measured NTE voltage. Connecting both secondary neutrals also demonstrates the interaction between farmsteads.

\section{SUMMARY}

The analog has been used in workshops to demonstrate that, in the absence of defective equipment, an NTE voltage is always present on power transmission and distribution systems. To solve the problem of excessive NTE voltage, an orderly approach is essential because of the analysis dif- 
TABLE I

EFFECT ON NTE VOLTAGES OF PHASE RELATIONSHIP OF SECONDARY NEUTRAL TO PRIMARY NEUTRAL CURRENT WITH LOCATION OF SECONDARY LOADS AT TAPS 2 AND 4 (FIG. 1)

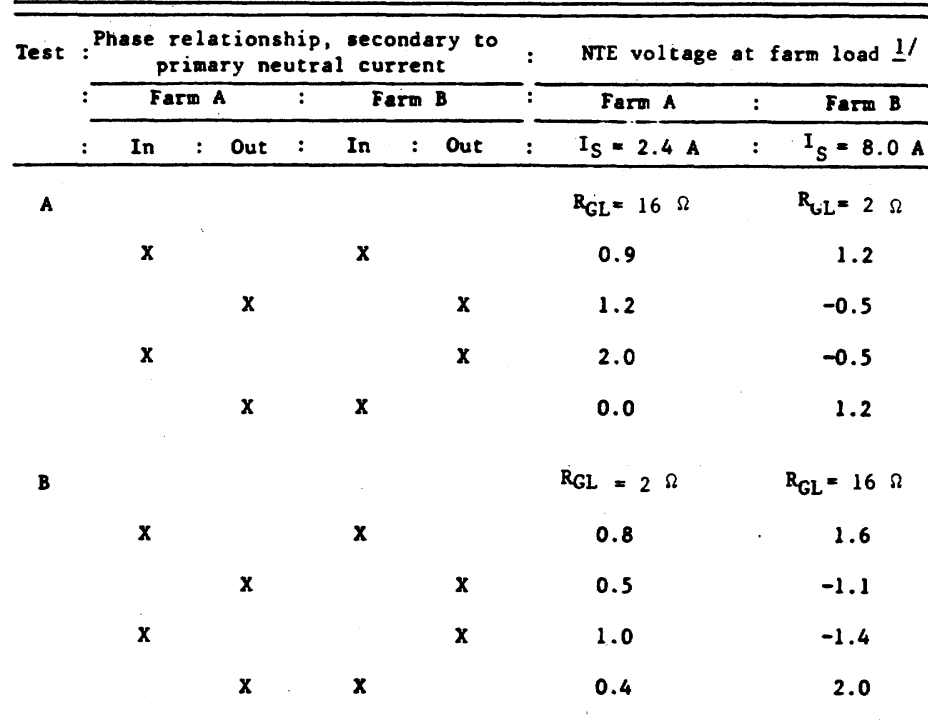

1/ $I_{S}$ is the secondary neutral current, RGL is the ground resistance at the farm load. Test conditions:

I Primary $=1 \mathrm{~A}$

RPG primary $=16 \Omega$ per ground

$R_{P N}$ primary $=0.4 \Omega$ per segment

$R_{G T}$ eecondary transformer $=16 \Omega$ per farm

RSN secondary $=0.2 \Omega$, both farms.

TABLE II

EFFECT ON NTE VOLTAGES AT SECONDARY LOADS WITH AND WITHOUT CONNECTION OF PRIMARY TO SECONDARY NEUTRALS, SECONDARY LOADS CONNECTED AT LOCATIONS 2 AND 4 (FIG. 1)

\begin{tabular}{|c|c|c|c|c|c|c|c|c|c|c|c|c|}
\hline \multirow{3}{*}{$\begin{array}{l}\text { Connected } \\
\text { to primary } \\
\text { neutral }\end{array}$} & \multicolumn{7}{|c|}{$\begin{array}{l}\text { :Phase relationship secondary to } \\
: \quad \text { primary neutral current }\end{array}$} & \multirow{3}{*}{$\begin{array}{r}: \\
: \\
:\end{array}$} & \multicolumn{4}{|c|}{ NTE voltage of farm load $1 /$} \\
\hline & \multicolumn{3}{|c|}{ Form A } & \multirow{2}{*}{$\begin{array}{l}: \\
:\end{array}$} & \multicolumn{3}{|c|}{ Farm B } & & \multicolumn{2}{|l|}{ Farm A } & \multirow{2}{*}{$:$} & \multirow{2}{*}{$\begin{array}{c}\text { Farm B } \\
I_{S}=2.8 \mathrm{~A}\end{array}$} \\
\hline & : In & : & Out & & In & $:$ & Out & & $I_{\dot{S}}=8.4$ & $\mathbf{A}$ & & \\
\hline \multirow[t]{4}{*}{$A$} & $x$ & & & & $x$ & & & & 2.8 & & & 0.3 \\
\hline & & & $x$ & & $x$ & & & & -0.2 & & & 0.3 \\
\hline & & & $x$ & & & & $x$ & & -0.2 & & & -0.3 \\
\hline & $x$ & & & & & & $\mathrm{x}$ & & 2.8 & & & -0.3 \\
\hline \multirow[t]{4}{*}{ B } & $\mathrm{x}$ & & & & $x$ & & & & 0.9 & & & 1.4 \\
\hline & & & $x$ & & $x$ & & & & -0.9 & & & 1.4 \\
\hline & & & $x$ & & & & $x$ & & -0.9 & & & 0.4 \\
\hline & $x$ & & & & & & $x$ & & 0.9 & & & 0.4 \\
\hline \multirow[t]{4}{*}{ Both } & $x$ & & & & $x$ & & & & 2.6 & & & 1.0 \\
\hline & & & $\mathrm{x}$ & & $x$ & & & & -0.4 & & & 1.3 \\
\hline & & & $x$ & & & & $x$ & & -0.2 & & & 0.2 \\
\hline & $x$ & & & & $\cdot$ & & $x$ & & 2.7 & & & -0.1 \\
\hline
\end{tabular}

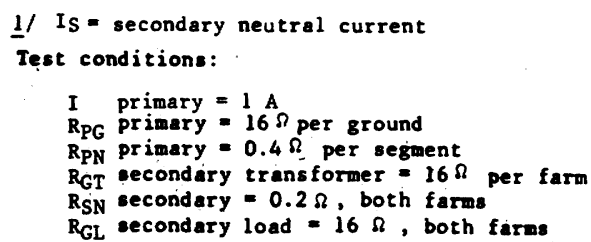


ficulties imposed by the many interactions. The goal is to reduce the voltage in livestock structures to a magnitude that is below the sensible animal threshold. Reduction can be achieved by assuring low impedance neutral circuits on and off the farm and by low-resistance grounding at the structure. Balancing loads to reduce secondary neutral current is also effective. Proper sizing of secondary neutral conductors serving these livestock structures is critical. Isolating transformers should only be used after assuring that both on-farm and off-farm wiring and equipment are safe and adequately designed, installed, and maintained.

The analog demonstrates the simplicity of the NTE voltage concept and the complexity of the analysis necessary to identify its source. The benefits of the analog as an educational tool will become increasingly evident as feedback is obtained from those who successfully solve an NTE voltage problem after participating in workshops where the analog was used.

\section{REFERENCES}

[1] W. Fairbank and L. B. Craine, "Milking parlor metal structure-toearth voltages,', Western Regional Agricultural Eng. Service, Oregon State Univ., Corvallis, Publication H-2, 1978.

[2] D. V. Henke, R. C. Gorewit, N. R. Scott, and D. M. Skyer, "'Sensitivity of cows to transient electrical current," Amer. Soc. Agricultural Eng., St. Joseph, MI, Paper 82-3029, 1982.

[3] P. F. McClernon, R. J. Gustafson, and H. A. Cloud, "A neutral-toearth demonstration unit," Amer. Soc. Agricultural Eng., St. Joseph, MI, Paper 80-3566, 1980.

[4] R. J. Norell, R. J. Gustafson, and R. D. Appleman, “Behavioral studies of dairy cattle sensitivity to electrical currents," Amer. Soc. Agricultural Eng., St. Joseph, MI, Paper 82-3530, 1982.

[5] R. S. Seeling, "Stray voltage on the dairy farm," presented at the IEEE Rural Electric Power Conf., 1980, Paper 80CH1532-1-IAC3.

[6] L. H. Soderholm, "Stray-voltage problems in dairy milking parlors," Trans. ASAE, vol. 25, pp. 1763-1767, 1774, 1982.

[7] L. E. Stetson, A. D. Beccard, and J. A. DeShazer, "Stray voltages in a swine farrowing unit-A case study," Trans. ASAE, vol. 24, pp. 1062-1064, 1979.

[8] L. E. Stetson, G. R. Bodman, and H. Shull, "Digital voltmeter for checking connections in neutral conductors,'” Amer. Soc. Agricultural Eng., St. Joseph, MI, Paper 82-3506, 1982.

[9] W. J. Szelich, Jr., "Ground potentials and currents," presented at the IEEE Rural Electric Power Conf., Paper 80CH1532-1-A-C2, 1980.

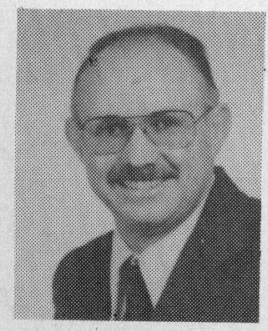

LaVerne E. Stetson (M'79) was born in Crawford, NB, on August 26, 1933. He received the B.S. and M.S. degrees in agricultural engineering from the University of Nebraska, Lincoln, in 1962 and 1968, respectively.

He joined the U.S. Department of Agriculture in 1962 and has since worked in farm electrification research. Until 1971, he was involved in research to control stored grain insects using radio-frequency energy. Since 1971, he has conducted research on electrical safety and reliability
Mr. Stetson received a USDA award for Outstanding Performance in 1967, and a USDA Certificate of Merit in 1972 for development of electrical standards for irrigation. He was the recipient of the 1979 Distinguished Service Award from the Food and Energy Council, and the 1979 Service Award from the Nebraska State Electrical Borad for his efforts in electrical safety. He also received the 1980 "Man of the Year" award from the Irrigation Association for his work in irrigation electrical safety. He is a member of the Rural Electric Power Committee of the IEEE Industry Applications Society. He is also a member of the American Society of Agricultural Engineers, IEEE Power Engineering Society, Tau Beta Pi, Sigma Tau, Sigma Xi, and Gamma Sigma Delta. He is a Registered Professional Engineer in the State of Nebraska.

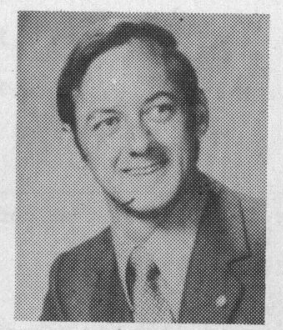

Gerald R. Bodman was born in Catawissa, PA, on May 22, 1944. He received the B.S. and M.S. degrees in agricultural engineering from the Pennsylvania State University, University Park, in 1966 and 1968, respectively.

His work experiences include design, sales, and installation of irrigation systems, teaching and extension work at Pennsylvania State University. He was a Construction Supervisor and Design Engineer for a farm builder in New England and worked as a cabinetmaker and home builder. His present position is Associate Professor and Extension Agricultural Engineer-Livestock Systems at the University of Nebraska, Lincoln. His responsibilities include both extension and research in the area of livestock housing and farmstead engineering. Additionally, he works part-time as a Consulting Engineer in agricultural production systems.

$\mathrm{Mr}$. Bodman was named the Young Extension Engineer of the Year in 1982 by the American Society of Agricultural Engineers. He is a member of the National Society of Professional Engineers, Professional Engineers in Private Practice, and American Society of Heating, Refrigeration, and Air-Conditioning Engineers. He is listed in Who's Who in Engineering, Who's Who in the Midwest, and Men of Achievement. He is a Registered Professional Engineer in 25 states and a licensed land surveyor and a pilot.

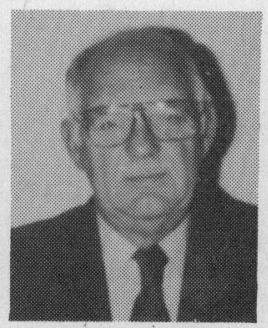

Hollis Shull received the B.S. degree from Iowa State University, Ames, and the M.S. degree from the University of Nebraska, Lincoln.

$\mathrm{He}$ was an Agricultural Engineer with the Agricultural Research Service of the U.S. Department of Agriculture. His primary career interest was irrigation research, conducted during assignments in California, Nebraska, and Minnesota. $\mathrm{He}$ has been interested in electronics for many years and has held an amateur radio license since 1939. He is now retired.

of irrigation equipment. 